\title{
Effect of Cusp Size, Depth and Direction on Stress Concentration
}

\author{
Md Shams E. Tabriz and Simon Barrans
}

\begin{abstract}
Recently multi-axial machining technology has improved significantly. It has become a widely accepted method of manufacturing components with complex, free form surfaces. Solid billet materials with negligible internal defects are used in this process. This provides increased durability and fatigue life over equivalent cast components. However, multi-axial machining leaves cusps as machining marks. The combination of tool size and step-over generates cusps with different depths and widths. Even though the cusps add extra material on top of the nominal surface, the Finite Element Analysis simulations presented in this paper show that the maximum stress generated within the cusps can be greater than that predicted from the cusp-free geometry. These stress concentrations generated by cusps can reduce the fatigue life and durability of a machined component.

In this paper a full factorial analysis of the effect of tool size, cusp width/step-over and cusp direction has been conducted. The analysis uses five different levels of tool size and cusps width and four levels of cusp direction. The results can be used to determine a tool size, cusp width and cusp direction combination with minimum spurious stress raising effect.
\end{abstract}

Index Terms-Cusp depth, cusp direction, cusp size, finite element analysis, stress concentration.

\section{INTRODUCTION}

Multi-axial machining processes using ball nose or bull nose cutting tools leave significant machining marks in the form of cusps. According to Vickers and Quan [1], cusps form between adjacent cutter paths across the surface. Squires [2] pointed out that the depth of the cusp depends on the combination of tool diameter size and the distance between each pass of the machine tool head or step over. Depending on the tool size and step over combination, a range of cusp depth form $1 \mu \mathrm{m}$ to $400 \mu \mathrm{m}$ can be generated.

Researchers have investigated the effect of the surface roughness of machined specimens on stress concentration and fatigue life. Bayoum \& Abdellatif [3], Javidi et al. [4] and Sasahara [5] have looked into the effect of surface roughness on fatigue life of aluminium alloy, nickel-molybdenum alloy and $0.45 \% \mathrm{C}$ steel respectively and concluded that the fatigue durability reduces with increasing surface roughness due to the stress concentrations generated by the rough surface. Novovic et al. [6] state that surface roughness values over $0.1 \mu \mathrm{m}$ influence the fatigue life on any component significantly. Schmid et al. [7]suggest using a Surface Finish Factor to include the effect of surface

Manuscript received December 9, 2016; revised April 18, 2017. This work was supported in part by the regional growth fund provided by UK Government (RGF Grant Award 01.09.07.01/1789C).

The authors are with the University of Huddersfield, Huddersfield, United Kingdom (e-mail: Md.S.Tabriz@hud.ac.uk, S.Barrans@hud.ac.uk). roughness on fatigue life. The equation is [8] :

$$
k_{f}=e S_{u t}^{f}
$$

Here, $k_{f}=$ Surface Finish Factor

$S_{u t}=$ Ultimate Tensile Strength of Material, MPa

$e \& f=$ Empirical factors depending on the manufacturing process. For machining $e=4.51$ and $f=-0.265$

Suraratchai et al. [9] and As et al. [10], both used Finite Element Analysis (FEA) of measured topologies of machined surfaces without cusps to calculate the stress concentration of aluminium alloy induced by surface roughness. The surfaces were measured using diamond stylus instrument and an optical surface profiler respectively. The authors used the stress concentration data to calculate the fatigue life of the component. Suraratchai et al. [9] used a solid aluminium bar for four-point bending fatigue test. In contrast, As et al. [10] used a cylindrical specimen for tensile fatigue test.

In the work discussed above, researchers have only looked in the effect of surface roughness of machined surface without cusps on fatigue stress. Machining cusps have a significant effect on the surface geometry of any component [1] which may impact on performance. For example, Childs $\&$ Noronha [11] investigated the effect of machining cusp on the aerodynamic performance of compressor impeller. However, significant research on the effect of cusp size, depth and direction on the stress concentration is absent. In this paper, FEA is used to investigate changes to the stress magnitude and distribution due to machining cusps.

\section{DeVElopment OF THE SPECIMEN}

Fig. 1 shows the specimen and dimensions of the traditional 'dog-bone' fatigue specimen developed for FEA simulation. The maximum stress is predicted to occur in the centre of the specimen where the width, is the smallest.

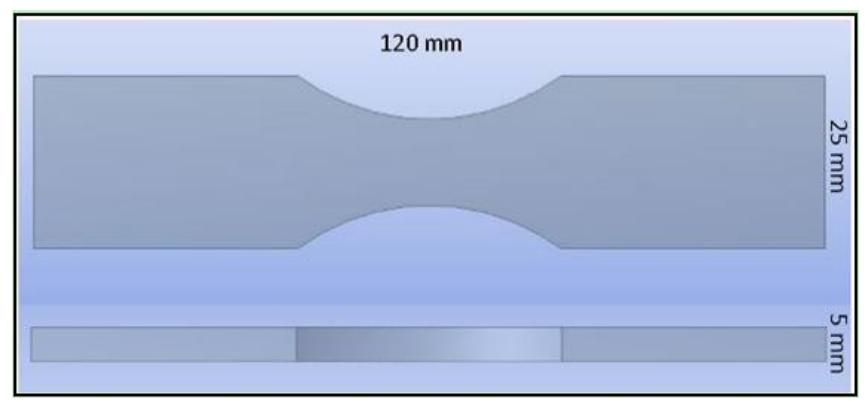

Fig. 1. Tensile specimen with dimensions.

\section{FEA SimULATION OF THE SPECIMEN}

The stress distribution of the tensile specimen was 
determined using Finite Element Analysis. The specimen is perfectly symmetric and a quarter of the model was used for FEA simulation. The benefits of using a quarter of the tensile specimen models over the whole specimen are:

- The constraints required to run FEA analysis of the quarter model are unambiguous and it allows constraining the model in a simple manner to prevent translation in the $\mathrm{X}, \mathrm{Y}$ and $\mathrm{Z}$ direction and rotation about those three directions.

- Using symmetry substantially reduces the FEA solution time and allows more control over meshing.

The load and constraints used for the simulation are shown in Fig. 2.

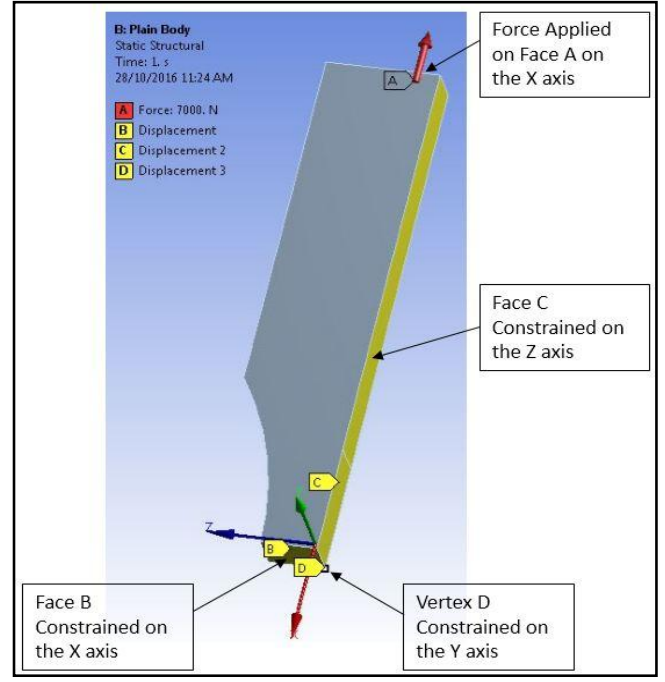

Fig. 1. The load and constraints used for the quarter model.

A mesh convergence study was conducted to identify the ideal element size for the notched area where high stress gradients were anticipated. Fig. 3 shows the mesh convergence results. Based on this convergence study, 0.4 $\mathrm{mm}$ element size was used in the notched area of the specimen.

The FEA results show maximum stress on the notch area. Fig. 4 shows the maximum principal stress and von-Mises stress from the quarter model.

\section{INTRODUCTION OF CUSPS ON THE SPECIMEN}

\section{A. Generation of Cusps}

Cusps were simulated on the specimen using Ansys Design Modeller (Ansys DM), as shown in Fig. 4. The circles diameters matched the tool diameter and the distance between circles was equal to the step over value. The complex geometry was than cleaned for a sweep cut operation. The sweep cut generated the cusps on the specimen surface.

Specimens with cusps not running perpendicular to the specimen axis were generated by altering the direction of the plane containing the cusps drawing. Fig. 6 shows the specimen with a $25^{\circ}$ cusp direction angle.

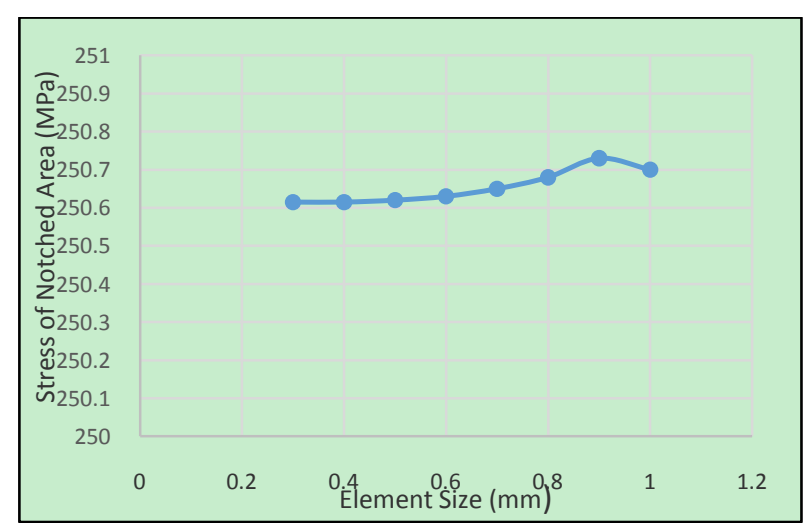

Fig. 2. Mesh convergence of nominal tensile specimen.

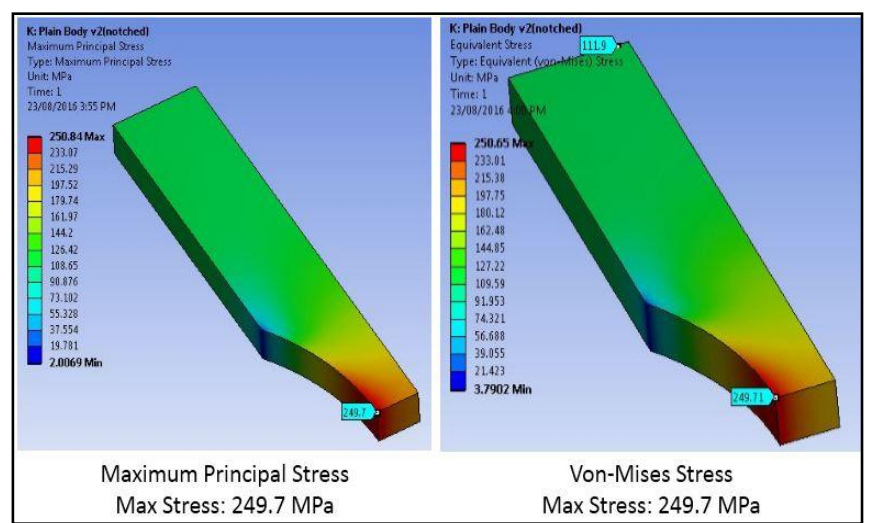

Fig. 3. FEA results of quarter segment of the specimen.

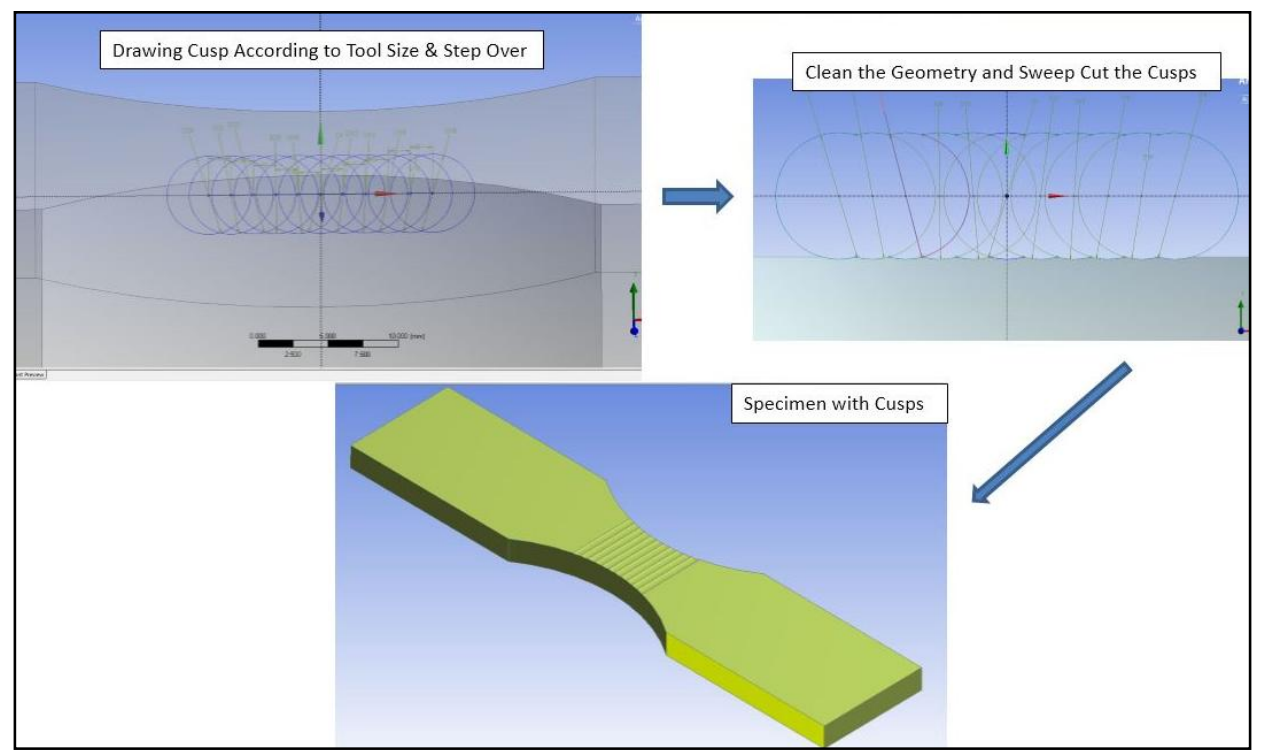

Fig. 5. Flow chart showing cusp generation in Ansys DM 


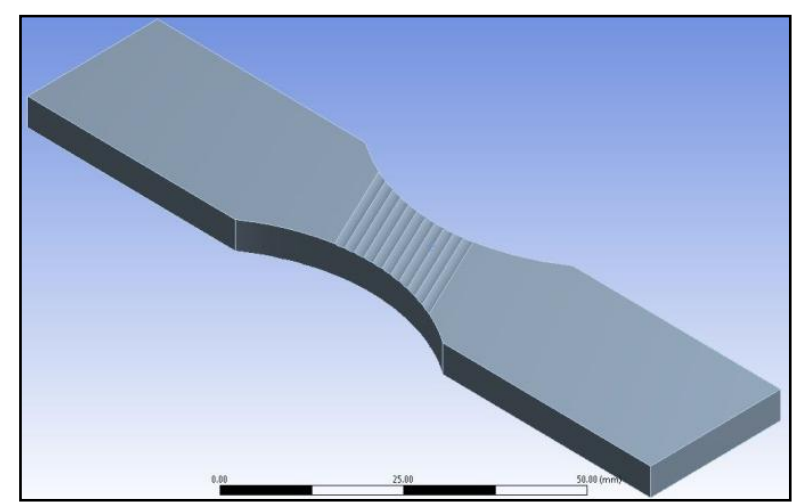

Fig. 6. Specimen model with cusps of $25^{\circ}$ angle direction.

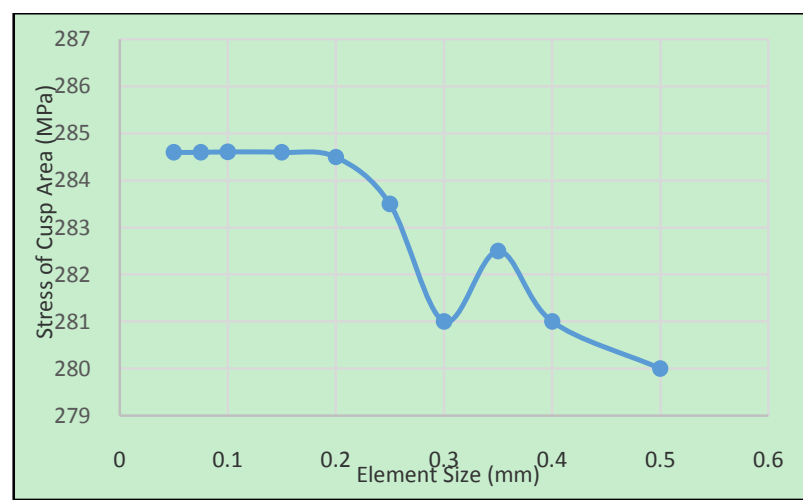

Fig. 7. Mesh convergence study of specimen with machining cusps.

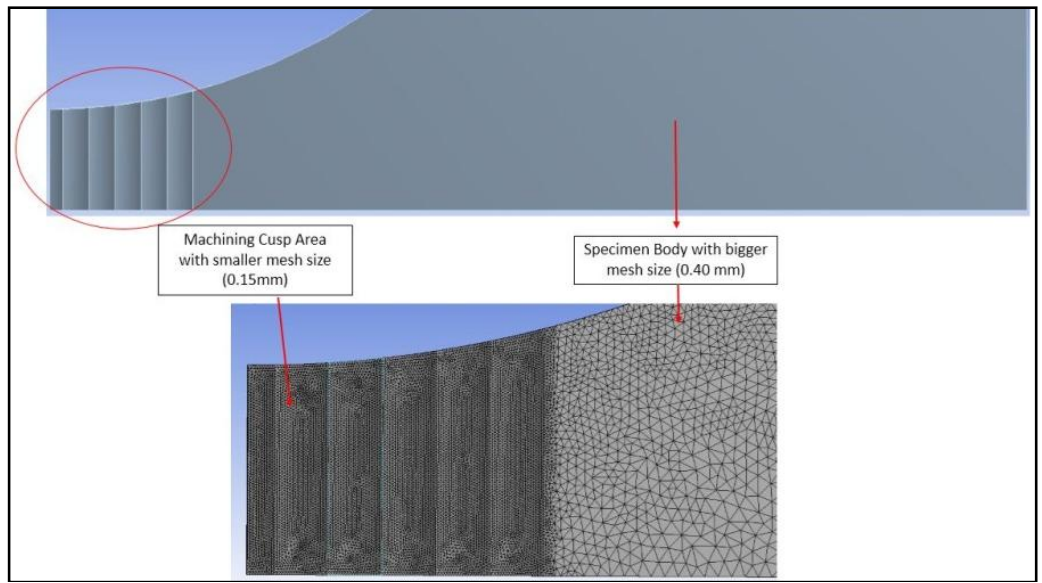

Fig. 8. Localised mesh sizing.

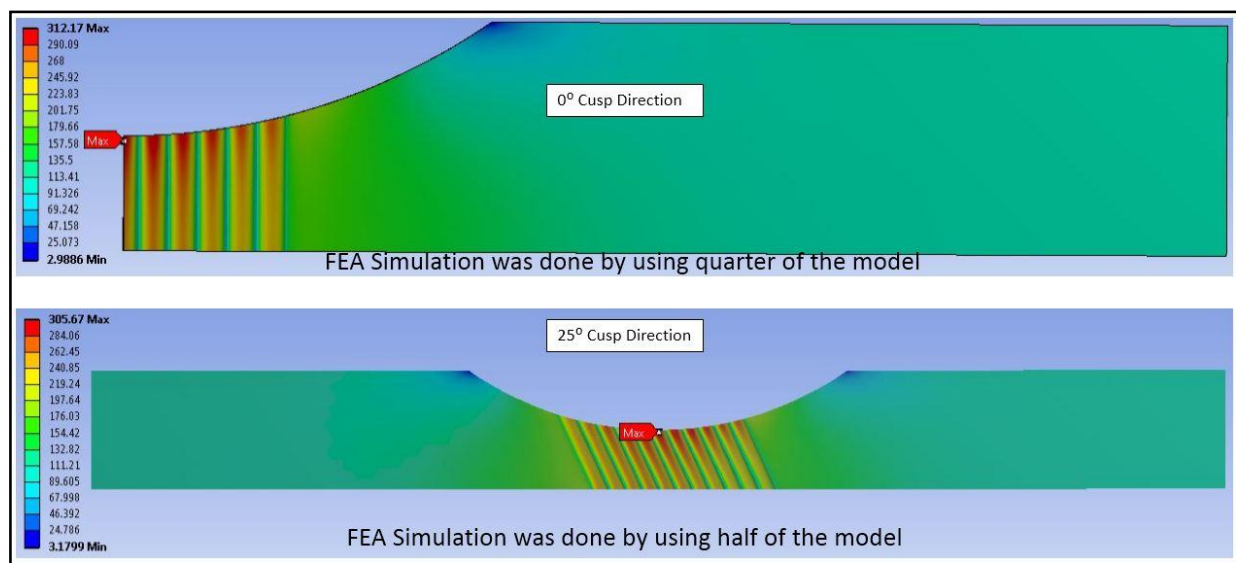

Fig. 9. FEA results of specimen with cusps.

\section{B. Simulation of Specimen with Cusps}

\section{1) Meshing specimen with cusps}

A fine mesh is necessary to represent the detailed cusp geometry on the specimen. Hence, a mesh convergence study was conducted on the element size in the machining cusp area and the element size of the rest of the specimen was kept as same as the nominal CAD geometry $(0.4 \mathrm{~mm})$. Fig. 7 shows the convergence study graph of the machining cusp area. Based on the convergence study, localised mesh sizing was specified as shown in Fig. 8.

The benefits of using localised meshing were:

- Smaller elements in the machining cusps better represented these cusps and allowed the effect of these to be captured.

- Simulation time was significantly reduced by using bigger elements in areas of low stress gradient.

\section{2) FEA Simulation of specimen with cusp}

A $6 \mathrm{~mm}$ tool diameter and $1.6 \mathrm{~mm}$ step over were used to generate a tensile specimen with cusps in Ansys DM. Quarter specimen models were used to simulate specimens with $0^{\circ}$ cusps direction. However, specimens containing cusps at other angles were not symmetric about the plane normal to the specimen axis. Hence, half of the specimen model was used for these specimens. Fig. 9 shows the stress distribution results of the specimen with generated cusps.

The simulation results have shown a significant increase of maximum principal stress in the cusp area in comparison with plain body specimen. The specimen with $0^{\circ}$ cusp direction shows an increase of $62 \mathrm{MPa}$ compared to the nominal geometry and the specimen with $25^{\circ}$ cusp direction shows an increase of $55 \mathrm{MPa}$.

These results established that machining cusps have a significant effect on stress distribution and the cusps works as 
stress raisers. In addition, the results show that the cusp direction has substantial effect on the stress raising effect.

\section{3) Sensitivity study of tool size and step over}

A sensitivity study of the effect of tool size, step over and cusp direction angle on stress was undertaken. Firstly, the step over/cusp width was kept fixed to $1.6 \mathrm{~mm}$ and a range of tool sizes from $2 \mathrm{~mm}$ to $35 \mathrm{~mm}$ diameter was used to determine the effect on cusp depth change. Fig. 10 shows the effect of tool size on cusp depth. Fig. 10 shows that if the step over is fixed, the cusp depth decreases as tool size increases.

Fig. 11 and Fig. 12 show the Maximum Principal Stress and von-Mises Stress distribution results from this fixed step over sensitivity study.

The results show that, for a given step over, the smaller the tool size the bigger the cusp depth and hence with the increment of cusp depth the stress value increases. The stress raising effect of cusps reduces with the increment of cusp direction angle.

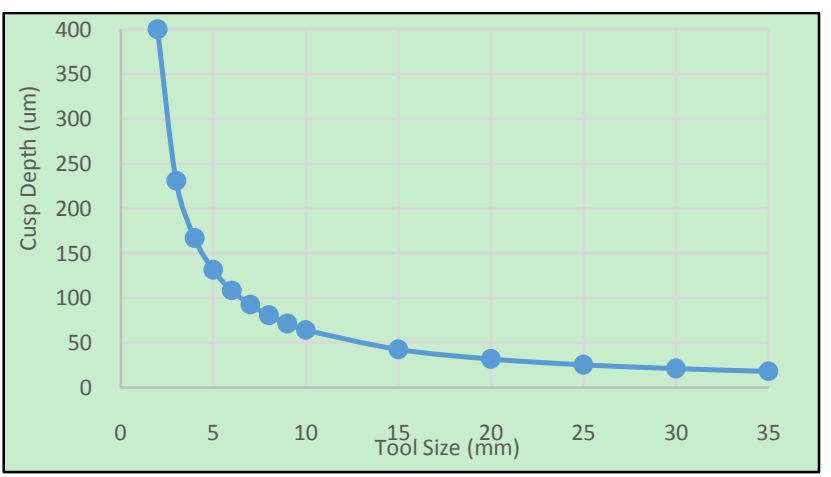

Fig. 10. Effect of tool size on cusp depth.

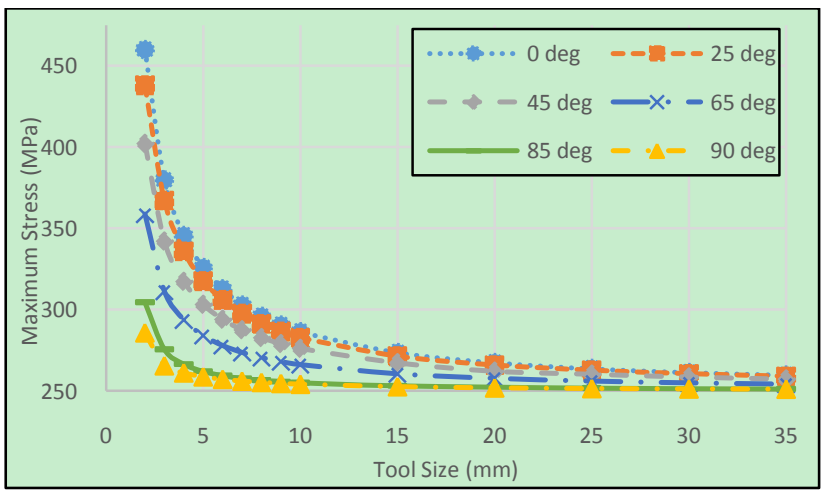

Fig. 11. Effect of tool size on maximum principal stress.

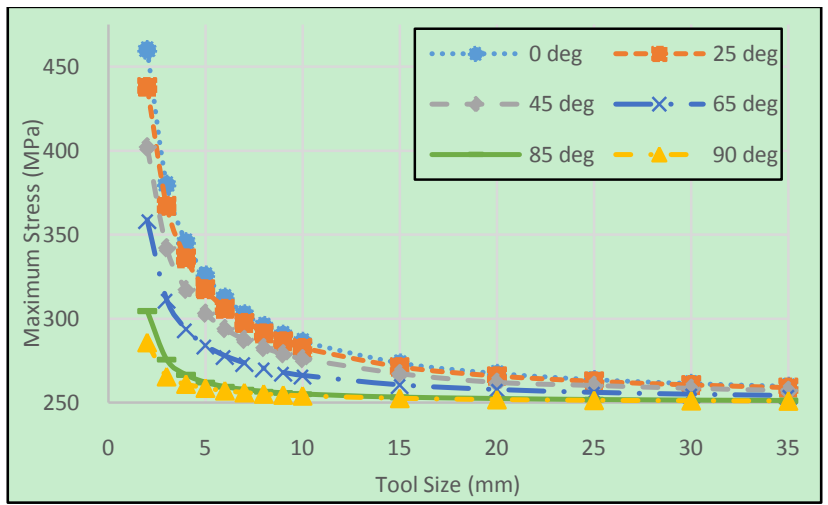

Fig. 12. Effect of tool size on von-Mises stress.

A second sensitivity study was conducted with the tool diameter kept fixed at $6 \mathrm{~mm}$ and the step over value varied from $0.2 \mathrm{~mm}$ to $2.4 \mathrm{~mm}$, again with multiple cusp directions. Fig. 13 shows that for a fixed tool size, cusp depth increases with step over. Fig. 14 \& Fig. 15 show the Maximum Principal Stress and von-Mises Stress distribution results from this sensitivity study.

The results shows that, for a given tool size, the cusp depth increases with the increment of step over and hence with the increment of cusp depth the stress value increases. The stress raising effect of cusps reduces with the increment of cusp direction angle.

TABLE I: FACTORS AND LEVELS OF FULL FACTORIAL ANALYSIS

\begin{tabular}{|l|l|l|l|l|l|}
\hline Factors & $\begin{array}{l}\text { Level } \\
\mathbf{1}\end{array}$ & $\begin{array}{l}\text { Level } \\
\mathbf{2}\end{array}$ & $\begin{array}{l}\text { Level } \\
\mathbf{3}\end{array}$ & $\begin{array}{l}\text { Level } \\
\mathbf{4}\end{array}$ & $\begin{array}{l}\text { Level } \\
\mathbf{5}\end{array}$ \\
\hline Tool Size & 2 & 5 & 10 & 15 & 20 \\
\hline $\begin{array}{l}\text { Cusp } \\
\text { Width }\end{array}$ & 0.2 & 0.8 & 1.4 & 2 & 2.6 \\
\hline $\begin{array}{l}\text { Cusp } \\
\text { Angle }\end{array}$ & $0^{\circ}$ & $25^{\circ}$ & $50^{\circ}$ & $75^{\circ}$ & \\
\hline
\end{tabular}

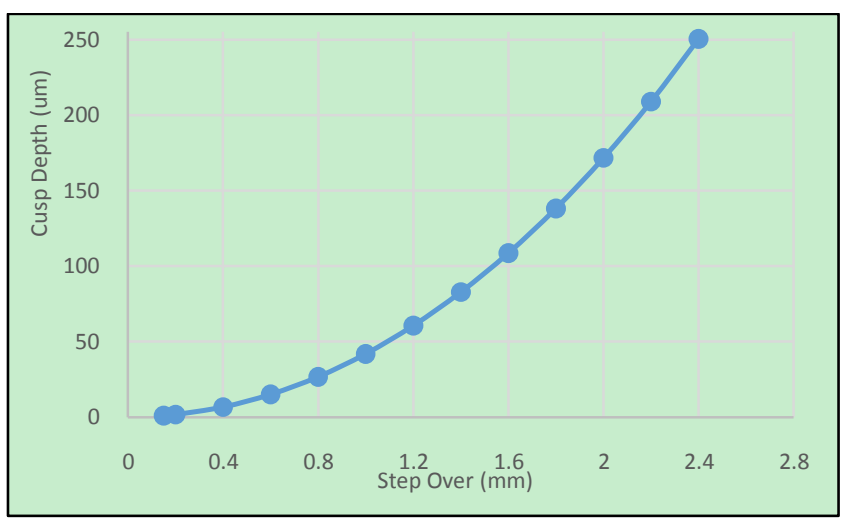

Fig. 12. Effect of step-over on cusp depth.

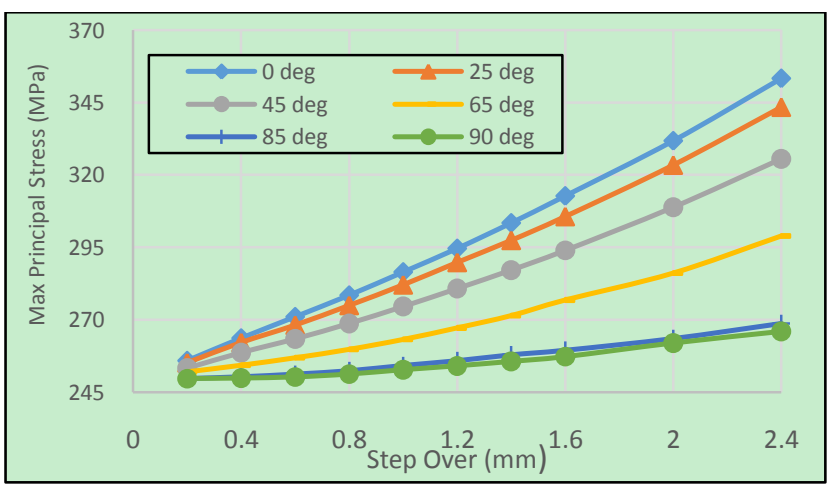

Fig. 14. Effect of step-over on maximum principal stress.

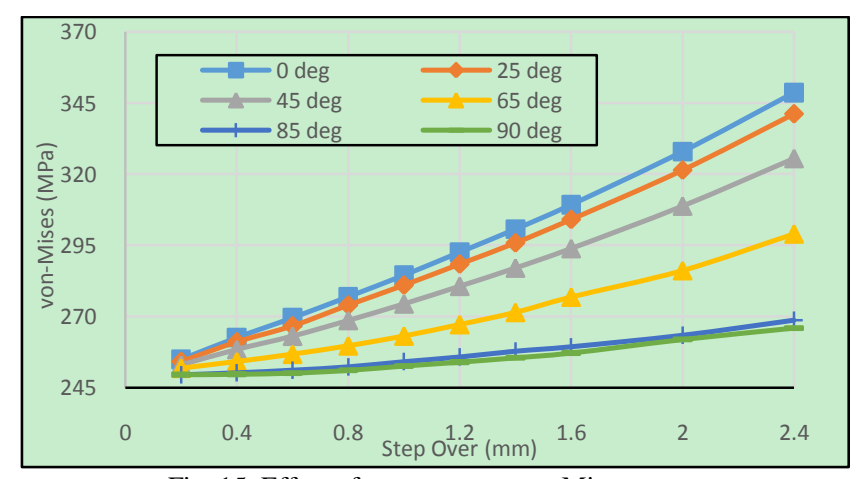

Fig. 15. Effect of step-over on von-Mises stress.

\section{Full Factorial Analysis}

The sensitivity study results showed that stress distribution and magnitude was dependent on tool size, cusp width (step 
over) and cusp direction. Hence, a full factorial analysis was conducted to further investigate these effects. Table I shows the factors and levels. In total, 100 separate simulations were undertaken.

\section{Full Factorial Analysis Results}

The maximum principal stress and von-Mises stress at $0^{\circ}$ cusp angle are shown in Fig. 16 \& Fig. 17. The full factorial FEA analysis shows that the stress concentration reduces when bigger tool sizes and smaller step overs are used. The cusps generated by the smallest step over of 0.2 and the biggest tool diameter of $20 \mathrm{~mm}$ generated around $250 \mathrm{MPa}$ stress at the bottom of the cusp. While, the cusps generated by biggest step over of $2.6 \mathrm{~mm}$ and the smallest tool size of 2 $\mathrm{mm}$ generated around $650 \mathrm{MPa}$ stress at the bottom of the cusp. The smallest tool and largest step over generate the greatest stress concentration with stress magnitudes $250 \%$ greater than the nominal CAD model. The results plot of both maximum principal stress and von-Mises stress shows similar stress raising effect.

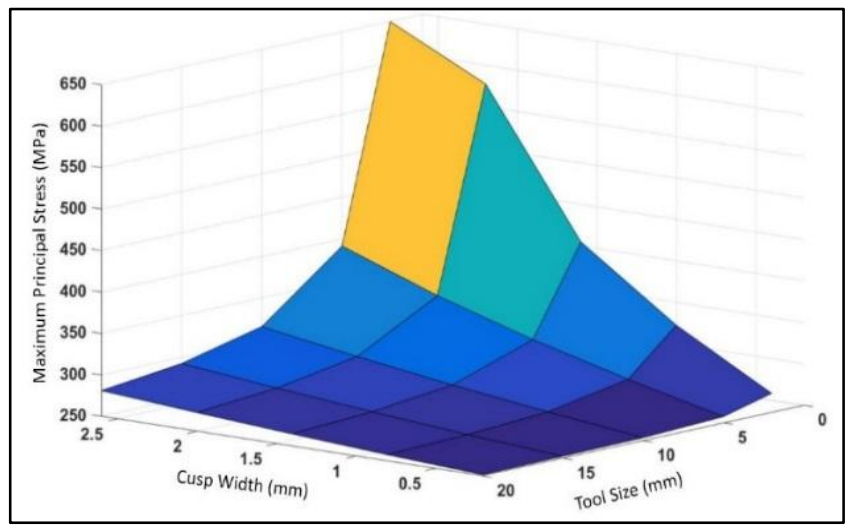

Fig. 16. Full factorial analysis of maximum principal stress.

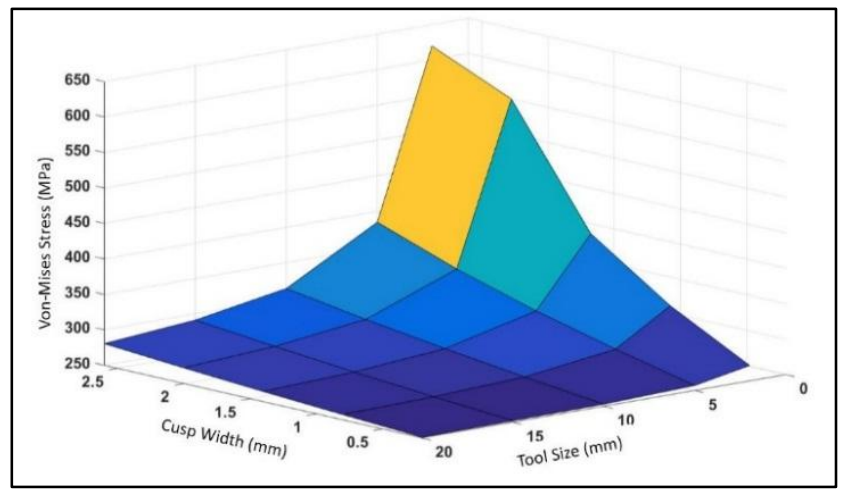

Fig. 17. Full factorial analysis of von-Mises stress.

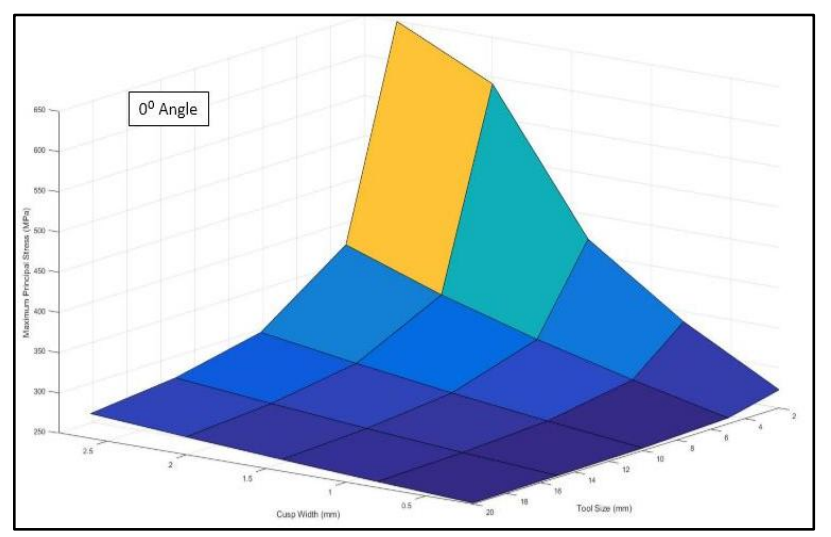

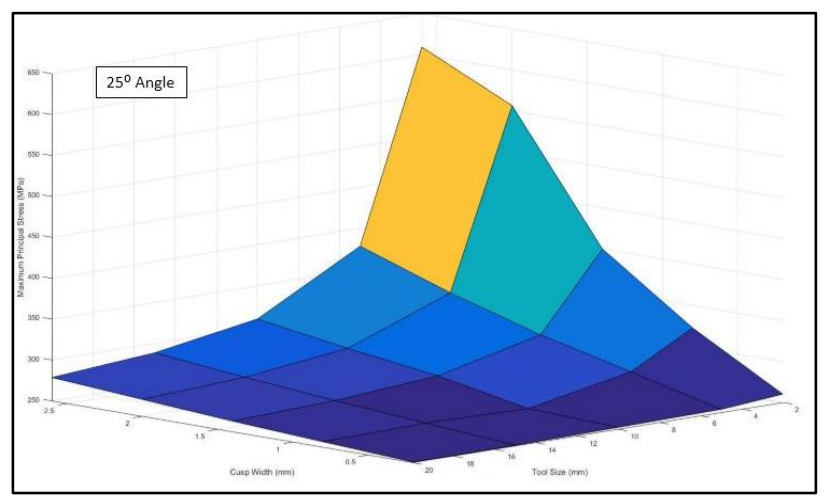
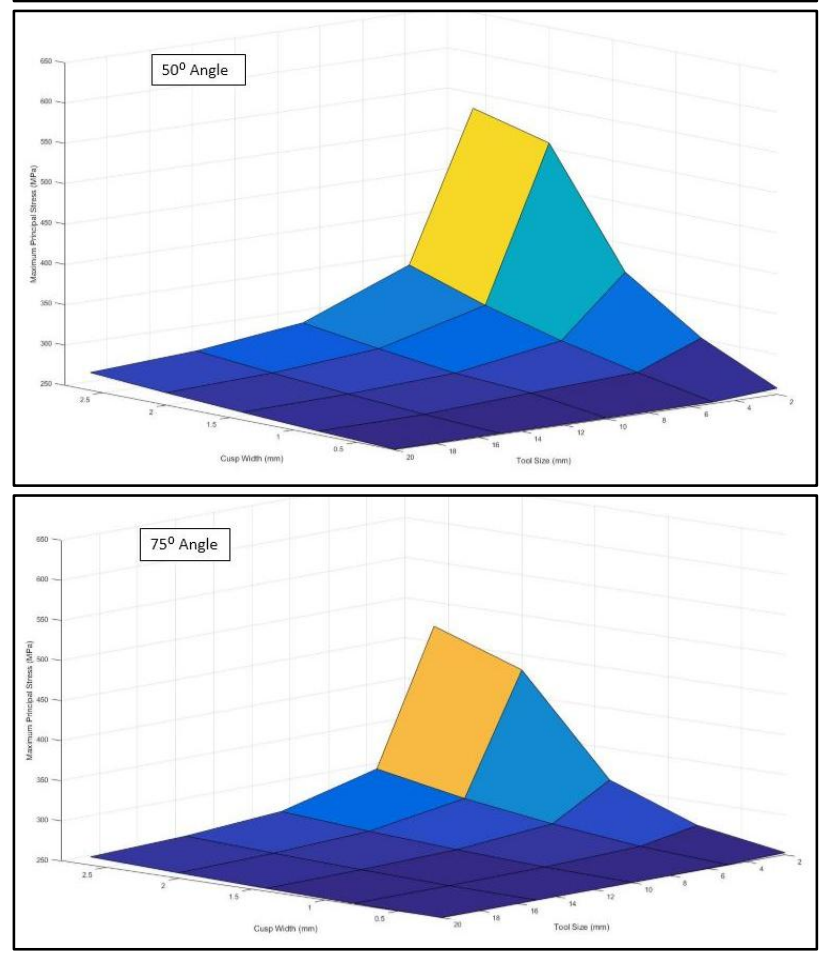

Fig. 18. Effect cusp direction on maximum principal stress.

Fig. 18 shows the effect of cusp direction angle on the maximum principal stress. Increasing the cusp direction angle (i.e. aligning the cusps with the specimen axis) minimises the stress raising effect of cusp depth. Cusps with $0^{\circ}$ cusp direction generates $650 \mathrm{MPa}$ of maxiumum principal stress with the combination of the smallest step over and biggest tool diameter. When the cusp direction were increased to $25^{\circ}, 50^{\circ}$ and $75^{\circ}$; the stress raising effect minimises significantly for the same step over-tool size combination. In comparison with cusps $0^{\circ}$ direction angle, cusp with $50^{\circ}$ direction angle reduces the stress concentration by $120 \mathrm{MPa}$ and cusp with $75^{\circ}$ direction angle reduces the stress concentration by $180 \mathrm{MPa}$. The study shows that, optimising the cusp direction can reduce the stress raising effect by up to $25 \%$.

\section{CONCLUSION}

Ansys deign modeller was used to replicate cusps with a variety of size and depth. Primary sensitivity of the effect of stress distribution on tool size and step over showed that, for a given step over, a smaller tool size generated cusps with greater depth and this increased the stress magnitude. In addition, for a given tool size, cusp depth and hence stress magnitude increased with step over. Both studies showed that 
the stress raising effect of cusps reduced as cusps were aligned along the specimen axis.

A full factorial analysis of the effect of tool size, cusp width/step-over and cusp direction on the stress distribution was conducted by considering five different levels for the factors tool size and cusps width and four different levels for the factor cusps direction. The results of this analysis can be used to determine a tool size, cusp width and cusp direction combination that minimises the stress raising effect due to machining cusps.

\section{REFERENCES}

[1] G. W. Vickers and K. W. Quan, "Ball-mills versus end-mills for curvesd surface machining," Journal of Engineering Industry, vol. 111, pp. 22-26, 1989.

[2] J. Squires. (2013). Understanding stepover and cusp height. [Online]. Available:

http://www.styrotechcnc.co.nz/our-blog/understanding-stepover-and-c usp-height

[3] M. R. Bayoumi and A. K. Abdellatif, "Effect of Surface Finish on Fatigue Strength," Engineering Fracture Mechanics, vol. 51, no. 5, pp. 861-870, 1995.

[4] A. Javidi, U. Rieger, and W. Eichlseder, "The effect of machining on the surface integrity and fatigue life," International Journal of Fatigue, vol. 30, pp. 2050-2055, 2008

[5] H. Sasahara, "The effect on fatigue life of residual stress and surface hardness resulting from different cutting conditions of $0.45 \% \mathrm{C}$ steel," International Journal of Machine Tools \& Manufacture, vol. 45, pp. 131-136, 2005.

[6] D. Novovic, R. C. Dewes, D. K. Aspinwall, W. Voice, and P. Bowen, "The effect of machined topography and integrity on fatigue life," International Journal of Machine Tools \& Manufacture, vol. 44, pp. 125-134, 2004

[7] S. R. Schmid, B. J. Hamrock, and B.O. Jacobson, Fundamentals of Machine Elements, 3rd ed., Boca Raton, FL, USA: CRC Press, 2014.

[8] J. E. Shigley and L. D. Mitchell, Machinical Engineering Design, 4th ed., London: McGraw Hill, 1983.

[9] M. Suraratchai, J. Limido, C. Mabru, and R. Chieragatti, "Modelling the influence of machined surface roughness on the fatigue life of aluminium alloy," International Journal of Fatigue, vol. 30, pp. 2119-2126, 2008.

[10] S. K. As, B. Skallerud, and B. W. Tveiten, "Surface roughness characterization for fatigue life predictions using finite element analysis," International Journal of Fatigue, vol. 30, pp. 2200-2209, 2008.
[11] P. R. N. Childs and M. B. Noronha, "The impact of machining techniques on centrafugal compressor impeller performance," in Proc. International Gas Turbine \& Aeroengine Congress \& Exibition, ASME: Orlando, Florida, USA, 1997.

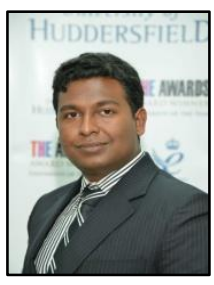

Md Shams E. Tabriz was born in Bangladesh. He earned his bachelor's degree in Mechanical Engineering from the University of Huddersfield on 2014. He is currently a $\mathrm{PhD}$ student in the Turbocharger Research Institute (TRI) of the University of Huddersfield. His research area is micro-crack initiation and propagation due to low cycle fatigue loading. The $\mathrm{PhD}$ project is funded by The UK government's Regional Growth Funding (RGF) and BorgWarner Turbo System.

Prior to start his $\mathrm{PhD}$, he has worked in General Motors UK as process and quality engineer.

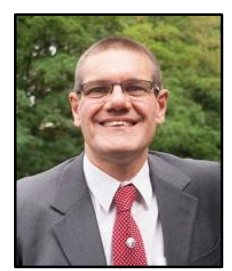

Simon Barrans gained a first degree in Nuclear Engineering at Manchester University and a $\mathrm{PhD}$ on 'enhancing finite element analysis boundary stress predictions' from the University of Huddersfield. After a period of time working for the UK Atomic Energy Authority at Windscale and Dounraey, he joined the academic staff at the University of Huddersfield in 1989. He has occupied various teaching and management positions including being Subject Area Leader in Mechanical and Automotive Engineering for eight years. He is currently the Reader in Turbocharger Engineering. He is an editor for the Open Engineering journal and a reviewer for seven international journals. He is also a member of the Institution of Mechanical Engineers Academic Standards Panel

Simon Barrans' current research is on the structural integrity of turbocharger systems with a particular focus on the methods used to join turbocharger housings together, predicting the stress raising effect of tool marks on machined from solid components and stress analysis of rotors for very high speed electric machines. He has also investigated the use of foil bearings in turbochargers, an extension of his previous research work on air bearings.

Simon Barrans regularly collaborates with industry on research and development projects. He has managed six Knowledge Transfer Partnerships with industrial partners funded by Innovate UK, two of which were graded as 'outstanding'. 